\title{
The Meaning of the Past: \\ The Perception and Appreciation of History Among Dutch Genealogists
}

\author{
Kees Ribbens, Gerben J. Westerhof and Cor van Halen
}

Public History Review, vol 12, 2006, pP27-43

\begin{abstract}
T he past is a diverse aggregate of experiences that have left very different traces. Similarly, the manner in which people deal with history is quite diverse as well. The way in which people encounter the past, and the meaning they attach to it, differs from person to person and from group to group. Whereas a certain person might be totally fascinated by the early modern naval history of the English, someone else may be mainly interested in the recent, everyday past of his or her own town. The ways in which people express their historical interest can also vary, from listening incidentally to personal testimonies to regular patronage of museums and archives. The way in which they approach the past and the intensity with which they do so, is connected to their appreciation of history. And at the same time the activities they perform to encounter the past may contribute to an increasing involvement with history.

Perception of the past, moreover, differs from period to period. Knowledge of history, as well as appreciation for past eras, is subject to change, an observation that is not only valid for the situation in the Netherlands, which is the territory on which we focus in this article. If, in a certain society, it concerns the interest in specific historical topics, such as World War II or the Dutch Revolt in the sixteenth and seventeenth century, the development of historical interest can usually be analyzed in a historiographical way.

Historical interest in general also seems to fluctuate over time. Numerous historians, cultural and social scientists, and other experts, both in the Netherlands and elsewhere in the western world, believe that history performs another role today than the one it used to play in previous periods. They allege that there is a decrease of ready knowledge about history, while on the other hand they perceive an increase in the number of museums, memorials, and commemorations. In the Netherlands, the observation that the past is handled differently today than in previous times is frequently accompanied by the assumption - usually expressed as a complaint - that the historical consciousness (in Dutch: 'historisch besef') is no longer what it once was. ${ }^{1}$
\end{abstract}


Remarkably, this concept of historical consciousness is hardly defined in Dutch society. This term seems to - or indeed for some must - include more than just the awareness that, apart from the present, there has also been a preceding past. The concept also has to do with the capacity to place and interpret various facts into a historical context, based upon the presence of a sufficient amount of historical knowledge. The mostly normative interpretation of historical consciousness is in this way inextricably linked to a certain level of historical knowledge. The observation that historical consciousness does not reach its mark, is above all a complaint that people have insufficient knowledge about (certain aspects of) the past. Often this alleged deficit is subsequently connected, sometimes even automatically, with history teaching, especially in secondary schools.

The apparent discomfort with the changing social position (and interpretation) of history in the Netherlands has resulted in an increasing popularity of inquiries, meant to provide more clarity on this issue. It has become quite popular in recent years to survey the ready historical knowledge of both school aged children and the adult population. With a combination of indignation and uneasiness, it is observed that not everyone possesses the required fundamental historical knowledge (which is supposed to consist mainly of political and cultural topics of national and international importance). This occasionally causes quite a lot of fuss, both in the Dutch and in foreign media. ${ }^{2}$

Such examinations of the factual knowledge about history only show us a limited part of the contemporary historical culture, a phenomenon that includes all the ways in which people deal with the past in the broadest sense of the word. Reflection on the inquiries mentioned above, shows that insufficient attention is being paid to the question regarding exactly what function(s) the assumed historical knowledge should have and to which degree such functions are considered relevant by the reviewed persons. In this way, too little attention is paid to the background and characteristics of the historical interest which is supposed to be questioned.

History is not - and has never been - exclusively related to the acquisition of knowledge. It also plays a role in the process of identity creation (which is closely connected to the search for a sense of continuity), a role in legitimising certain situations or claims, as well as a role in the pursuit of aesthetic and recreational pleasures. It is therefore not strictly necessary to impose a univocal criterion of historical consciousness which regards one manner to deal with the past as more preferable to another. Because history does not exclusively have a function as knowledge, it encompasses more than solely the history syllabus taught in schools. This educational content is certainly an important element in historical culture, but it is, especially nowadays, complemented with information from a myriad of other sources. The past is not always presented within the familiar framework of the nation-state (in this case: the Dutch nation) or Western civilization in these other sources. Also, the degree of seriousness with which the past is approached in the various manifestations of historical culture can differ 
from the historical transfer in the educational setting. This is clearly demonstrated by the manner in which theme parks, advertising experts and TV-producers frequently refer to historical elements in a frivolous way. Expressions of the historical culture which deviate from the traditional transfer of knowledge in schools are not by definition superior or inferior in their form or content. But in the eyes of those who 'consume' it, or otherwise spend their (leisure) time on it, these alternative expressions can possibly be more interesting or more relevant. How else can the popularity of history which tells people something about their own environment - their family, place of residence, profession, or leisure activities be explained? The considerable membership of local historical societies and the large-scale presence of genealogical researchers in numerous Dutch archives are also a clear proof of this.

Many activities which express historical interest are measurable in a quantitative and sometimes also a qualitative way. Visitor counts at museums and archives, membership of historical and genealogical societies, the number of historical books being published during a certain period, the topics of historical exhibitions, all these data contribute to a picture of the scope of historical interest. Unfortunately these data do not say much about the underlying motives of the actors involved.

Little research has been done exploring the motives on which the appreciation for different versions of historical culture are based and on the distribution of these appreciations among the several segments of society. The number of studies in this area, based on survey research among average citizens, is still relatively limited. The first of such studies was undertaken by archaeologist Nick Merriman who distributed a questionnaire by mail in 1985 to 965 British adults concerning their attitudes towards history in general and museums in particular. ${ }^{3}$ Almost a decade later, in 1994, the American historians David Thelen and Roy Rosenzweig conducted a survey by telephone among 1453 persons, which has recently helped to inspire the project 'Australians and their past'. ${ }^{4}$ Both the British and American studies show a great interest in the past, especially where the respondents can interpret the past in a rather personal way.

The results of these previous research projects stimulated our curiosity about what the present situation would be like in the Netherlands, a curiosity that can furthermore be explained by the lack of similar research on earlier periods. In 2002, the Department of History and the Department of Psychology at Radboud University Nijmegen decided to develop a questionnaire to gather more data on the public interest in, and attitudes toward the past in the Netherlands. ${ }^{5}$ Thanks to the cooperation of the Nederlandse Genealogische Vereniging - the Dutch Genealogical Society or NGV which is the largest national association of its kind, comprising a considerable per centage of Dutch people who research their family tree as a hobby - a twenty-four page version of the questionnaire entitled 'The meaning of the past' was distributed by mail in December 2002 amongst a 
sample of 300 individual members reflecting the geographical distribution of the membership. ${ }^{6}$

This research focuses on the meaning people attach to the past and on the emotions and activities connected to this. The survey also focuses on the way in which people encounter the past and what this means to them. Since sixty-four per cent of participating genealogists responded within a two month period, it is obvious that the respondents were very well motivated to fill in the questionnaire. ${ }^{7}$ This indicates that genealogists, at least in this respect, are not an average group reflecting the attitudes and opinions of Dutch citizens as a whole. ${ }^{8}$ Apart from their specific historical hobby and interest, which has positively influenced their motivation to cooperate in this relatively extensive research, they also differ from the average Dutch person with regard to education, age and gender. Exactly to what extent these differences with fellow Dutch people influence the views on history is difficult to determine as long as we lack similar data on nongenealogists. In order, however, to make a modest start with such a comparison, a limited selection of the survey questions have also been distributed amongst a small number of Dutch non-genealogists.

\section{General Characteristics of the Sample}

One hundred and ninety-two persons returned our questionnaire. All respondents are genealogists active in investigating their family tree. Almost all respondents discuss their activities with different generations within the family. The age of the active genealogists varies between 29 and 86 years, with a mean of 62 years. One out of four respondents is younger than 55 , one fourth between 55 and 62 , one quarter between 63 and 70 , and the last quarter older than 70 years. $^{9}$

Twenty-two per cent of the respondents were women. The women are somewhat younger than the men (58 and 63 years). The small proportion of women in our sample mirrors the fact that women are a minority in Dutch genealogical societies as well as among visitors of archives. This differs from findings in North-American studies which showed that there are more women than men among genealogists. ${ }^{10}$

One in ten respondents had completed primary or lower vocational education. Twenty per cent followed a middle vocational trajectory and one in four respondents had attained a secondary education (high school). Half of the respondents had higher educational levels (ranging from higher vocational institutions to university). This means that the educational level was generally high, as was also found in a Canadian study among genealogists. ${ }^{11}$ There are no clear differences according to age but men have higher educational levels than women. The respondents held a variety of occupations. ${ }^{12}$

To study variation within the group of Dutch genealogists, we created two age categories (below 62 years and 62 or older) and two educational categories (higher education or not). We also compared men and women. 


\section{CONNOTATIONS OF PAST AND HISTORY}

What are the connotations of the concepts 'past' and 'history' ('verleden' and 'geschiedenis' in Dutch) to these genealogists? Does their meaning overlap, or are they two distinct concepts? To answer these questions, a list of forty-five different words was presented to the respondents. They were first asked whether they associate these words with 'past' and then whether they associate them with 'history'.

More than half of the respondents answered that the concept 'past' was related to the following ten terms (in order of frequency): my ancestors, fascinating, archives, old documents, older generations, nostalgia, memories, the old days, old buildings, sense of connection. Ten terms were related to 'past' by less than ten per cent of the Dutch genealogists: old-fashioned, future, a burden that people have to bear, imagination, alienation, strangeness, amusement, chaos, boring, disgust. The concept 'history' had partly the same, partly different connotations than the concept 'past'. More than half of the respondents answered that history means to them: fascinating, archives, old documents, dates, ${ }^{13}$ versatile, my ancestors. The ten terms that were not related to the concept of 'past' by more than ten per cent of the genealogists, were also not related to the concept of 'history' by more than ten per cent. Furthermore, the terms myself and self-knowledge were related to 'history' by less than ten per cent.

Both concepts held rather positive meanings for a majority of the respondents and negative meanings for only a small minority. Furthermore, the particular historical topics of interest and historical sources of the genealogists are clearly found in associations like archives, old documents and ancestors.

Although both concepts have much in common, there are also a number of differences in their connotations. The concept of 'history' bears a meaning of versatility. However, less terms are associated to 'history' than to the concept of 'past', so that it also carries on a more specific meaning according to our respondents. To gain insight on this more particular meaning of the concept of 'history', the significant differences between both concepts are presented in Table 1. Dates' are associated with 'history' by twenty-two per cent more respondents than to 'past'. Historians, education, broad picture, important historical persons, certain books or movies, versatile, war monuments and statues are also more strongly related to 'history' than to 'past'. These findings show that history is related more to the knowledge of facts and figures that are also part of official, institutionalised history, as it is transferred in schools and studied by historians.

There are also a number of terms which are related to 'past' by more respondents than to 'history'. These are my ancestors, memories, nostalgia, antiques, older generations, my family, old buildings, the old days, traditions, reminiscing, archives, self-knowledge, myself and imagination. In other words, the family and the self combine with memories, traditions, and objects that are passed on, to make up the meaning of the concept 'past'. The 'past', rather than 'history', is related to the person or the personal and the interests of the genealogist. 
There are hardly any differences in this pattern of connotations of both concepts according to age, gender and educational level. The only significant difference is that more official connotations of the concept 'history' are shared by more persons with higher education than by those with less education.

TABle 1: Per Centage Respondents associating A WORD WITH 'PAST' OR 'HISTORY'

\begin{tabular}{lcc}
\hline & Past & History \\
Archives & 83 & 75 \\
My Ancestors & 85 & 52 \\
Older Generations & 63 & 47 \\
The old days & 56 & 45 \\
Old Buildings & 55 & 43 \\
Versatile & 45 & 54 \\
Sense of connection & 52 & 43 \\
Nostalgia & 58 & 35 \\
Dates & 34 & 56 \\
Memories & 57 & 28 \\
Traditions & 46 & 35 \\
Important Historical Persons & 32 & 44 \\
Antiques & 45 & 29 \\
Old & 39 & 29 \\
War Monuments & 26 & 34 \\
Certain Books or Movies & 25 & 35 \\
Historians & 18 & 37 \\
Broad picture & 20 & 34 \\
Warm feelings & 33 & 21 \\
My Family & 33 & 20 \\
Statues & 20 & 27 \\
Reminiscing & 29 & 18 \\
Education & 11 & 30 \\
Myself & 13 & 8 \\
Self Knowledge & 12 & 5 \\
Old-Fashioned & 9 & 4 \\
Imagination & 5 & 1 \\
Boring & 0 & 4 \\
& & \\
\hline
\end{tabular}

It can be concluded that Dutch genealogists share a rather broad frame of reference. Both concepts of 'history' and 'past' share a positive meaning but 'past' has a more intimate, quotidian orientation than the more official and detached concept of 'history'. 


\section{INTERESTS}

In the questionnaire, we also asked about specific historical interests of Dutch genealogists with regard to historical periods, geographical regions and historical themes. These questions were answered on a four-point scale, indicating whether a person was not, somewhat, strongly or very strongly interested in the particular aspect of the past. We present the per centage of persons who had a (very) strong interest in the particular aspects in Figures 1 to 4 . (See list of figures below and the related supplementary file.)

FIGURE CAPTIONS

For figures click on abstract at Table of Contents; reading tools; supplementary files.

Figure 1: Per centage of Dutch genealogists with a (very) strong interest in historical periods

Figure 2: Per centage of Dutch genealogists with a (very) strong interest in geographical regions

Figure 3: Per centage of Dutch genealogists with a (very) strong interest in historical themes

Figure 4: Per centage of Dutch genealogists who (very) strongly value memories from specified life phases

Figure 5: Per centage of Dutch genealogists who consult a certain source of information several times a month

Figure 6: Per centage of Dutch genealogists who at least six times a year visit historical places or participates in historical activities

With regard to historical periods, three out of four Dutch genealogists share a strong or very strong interest in the period between 1500 and 1800 and in the nineteenth century, followed by the first half of the twentieth century (see Figure 1). About half of the respondents are interested in the Middle Ages or in the postwar period. Prehistory and antiquity hold the interest of about a quarter of the Dutch genealogists. Older persons are somewhat more interested in the Middle Ages and the post-war period than younger persons, whereas the more educated respondents are more interested in antiquity and in the post-war period than persons with less education.

The most crucial period for Dutch genealogists is on the one hand the period from 1800 to 1900 , an era that can generally be documented rather well. On the other hand, the early modern period is of interest to Dutch genealogists too, as the reconstruction of one's family tree poses more intriguing problems, but also gives unexpected rewards. 
The strongest geographical interest for Dutch genealogists concerns the place where they grew up (see Figure 2). The interest in one's own region and the Dutch nation in general - the latter being an important issue of in history education in primary and secondary schools - does not differ much from this first interest. One's current place of residence is somewhat less interesting for Dutch genealogists than one's place of birth. The western world and in particular the non-western world are of less concern to Dutch genealogists. In general, the pattern shows that as the geographical distance becomes larger, the interest of the Dutch genealogist wanes. This is true, irrespective of age, gender or educational background. Higher educated persons are only somewhat more interested in the history of the western world. When the family originates from the region where one was born the interest in the place of birth and the surrounding region is even stronger and the interest in national and foreign history is weaker. We conclude that a strong attachment to place is found in the geographical spread of historical interests of Dutch genealogists.

The same interest in the local past is also found in the historical themes that Dutch genealogists find interesting (see Figure 3). The past of one's own family is clearly the most interesting topic to them, followed by one's personal past. It should be remembered here that the concepts of 'past' and 'history' were seldom associated to 'myself'. The personal past might have been interpreted in a broader sense than just one's own biography which is also confirmed by the relatively weak interest in the post-war period. We therefore believe that respondents interpreted their personal past mainly as a continuation of the past of one's own family.

About half of the respondents had a very strong interest in the everyday life, customs and traditions of the past. There was less interest in art and culture, nature, politics, religion and architecture. People were least interested in military and economic history as well as in leisure and gender. Older genealogists were more interested in religion, nature and politics than younger genealogists.

Persons with more education were more interested in art and culture as well as in political and economic history. Women were more interested in the history of their own gender and in everyday life whereas men were more interested in political and military history. It can be concluded that the interest in familial and personal daily life is stronger than that in more general and abstract societal historical themes, in particular for younger, female and less educated persons.

The interest in one's own family can be further specified as we also asked how often persons talked about the past with family members. Three out of four genealogists do this regularly or often. When asked whether one could imagine the life of previous generations, it was found that this was more difficult when the generations were further away in time. Three out of four respondents could imagine very well how the lives of their parents were, about two out of five succeeded with regard to the life of their grandparents, but only one in nine had a very good idea of the life of earlier generations. Somewhat more men than women claim that they know about the life of their earlier ancestors. When the 
family originated from the region one presently lived in, people talked more often about the past with their families and found it easier to imagine the lives of all previous generations. There is a strong interest in improving this situation, as ninety per cent of the respondents acknowledged that they wanted to know much more about earlier generations.

The interest in one's personal past can also be specified. We asked which periods in one's life are valued most (see Figure 4). The differences are small but there is a slightly stronger interest in one's adolescence (18-25 years) ${ }^{14}$ Almost three quarters of the Dutch genealogists favour this period which is more than the periods before and after. Women and more highly educated persons are somewhat more interested in their early youth but there are no age differences. When asked directly, only about one in three genealogists answered that the life phase with the most valued memories has led to a more general interest in the corresponding historical period. This finding, for genealogists with a mean age of 62 years, matches the relatively low interest in the post-war period. Apparently, one's own past does not automatically create an interest in history in general.

We conclude that the interests of our respondents are indeed genealogical interests per se. They are mainly interested in the period between 1500 and 1900. This period encompasses the nineteenth century that is rather easily accessible for Dutch genealogists as documents are relatively well conserved. The centuries before are more difficult to research but this appears to contribute to the fascinations for the tenacious genealogist. One's own place and region of birth - particularly when one's own family originates there - have their special interest and more private themes clearly prevail over more abstract, general themes. There is some variation among genealogists in that older and better educated persons as well as men have a broader historical interest for more general, abstract and public issues. It can be concluded that Dutch genealogists are more interested in the personal and familial 'past', as they defined it themselves, than in 'history' with its more official and detached connotations.

\section{Historical ACtivities AND TIES WITH THE PAST}

Our survey also asked about the sources of information on which the genealogists base their historical knowledge and views of the past. The history lessons in primary and secondary school seem to be the most common way to become acquainted with the past. However, the respondents differed in the duration of the historical education that they received. The majority of them did not pursue their historical training up to the highest grade of secondary school.

For many genealogists, the interest in the past germinated at school. Forty per cent of the respondents indicated that their interest in the past was excited by the history lessons that they received. For only one out of three, this was not the case or only to a limited degree. There were no systematic differences in age, gender or educational level in this respect. However, the respondents who had historical training up to the highest grade did indicate more frequently that the lessons evoked their historical interest than those who did not. 
A less positive picture emerged when we asked the respondents whether they thought that their historical training at school contributed to their present knowledge of the past. Two thirds of them did not consider school as the most important source of historical knowledge. Again, those who had historical education up to the highest grade considered the history lessons as an important source of knowledge about the past. No further notable differences could be found with respect to age, gender or education. The relatively poor appreciation of historical education at school is probably not unrelated to the content of this education. After all, the grand themes that the historical education at school is focusing on do not directly match the more personal historical interests of genealogists.

Where does one obtain information apart from the regular consultation of primary sources? Three-quarters of the genealogists read articles about the past in journals and magazines several times a month (see Figure 5). In view of the frequency, this will probably concern general periodicals rather than specifically historical and/or genealogical ones. Half of the respondents equally often consult books. Next, they turn to websites and television programs, attesting to the familiarity of genealogists with new media. Movies and radio programs are less often used as a frequent source of information about the past. People with higher education listen to the radio and read articles in journals and magazines comparatively more often whereas websites are less often consulted by older respondents. Otherwise, this pattern of media consumption remains the same in the different groups irrespective of the duration of one's historical education at secondary school or whether these lessons are considered as the primary source of information about the past. Still, two additional findings deserve mentioning. In those cases where history lessons did excite interest in the past, one more often watches movies and television programs and reads articles. Also, the respondents who do not consider school as the primary source of information about the past indicate that for them the most important source of historical knowledge consists in respectively reading various publications and in their own genealogical activities.

Are there other ways of 'doing' history besides absorbing information about the past? It is hardly surprising that visiting the archives is a popular activity among genealogists (see Figure 6). More than half of the respondents do this at least six times a year. About one quarter of the genealogists frequently visits a historical building and nearly ten per cent of them visit a historical museum. Public commemorations and historical theme parks are rarely visited. There were no age or gender differences in this way of becoming acquainted with the past. But there is one difference related with educational level: the respondents with the highest education are the most frequent visitors to historical buildings.

We also asked to what extent a connection with the past is felt when undertaking such historical activities. Reading a book or article and visiting the archives are ranked highest: it brings more than four out of five genealogists closer to the past. These activities are followed by the bond that is experienced 
when visiting historical locations and museums. Visiting historical buildings, commemorations and especially historical theme parks appear to have little impact. One could generally say that when the sources of information including articles, books and archives and other possibilities to feel a bond with the past are used more frequently, genealogists feel more connected to the past. In view of the special significance of the archives for genealogists, it should, however, be noted that this is not a gradual scale. Generally, most respondents appear to let their choice of sources of information and historical activities depend largely on the extent to which such sources and activities bring them closer to the past.

All in all, we may conclude that our respondents, by now grown into seasoned genealogists, do not have a particularly high opinion about the importance of the history lessons that they had at school. It is not clear whether this is a typical case of under-appreciating the value of the foundations that have been laid or the lack of appealing education. Still, we have the impression that an interest in the past was developed only later in life, after which the information is primarily sought in the printed media. The archives remain the most prominent source of information for the genealogist - even when the frequency in which the archives are visited is lower than in which publications are consulted. With respect to the latter, educational level is an influential factor in how one becomes acquainted with the past.

\section{Attitudes Towards the Past}

Finally, we have presented the participants with a series of statements concerning their attitudes towards the past (see Table 2). They were asked to indicate to what extent they agree with various assertions about the importance of the past. Statistical analysis has shown that the responses to twelve of these statements could be clustered into three separate components. ${ }^{15} \mathrm{~A}$ closer study of these components firstly reveals that the past can be regarded as a source of knowledge, for the present as well as the future. This is for instance clearly expressed in a statement like: 'Historical knowledge is of importance to understand the contemporary world'. Genealogists generally tend to agree with this position. Characteristic for these statements is that a logical connection between present and past is emphasized, and with that a certain continuity.

A second aspect concerns the past as a kind of contrast. In this cluster of statements, change and the difference between present and past is accentuated rather than continuity. A characteristic statement is for instance 'In the past, everything was different'. Here, too, genealogists tend to agree but slightly less than with the idea that history can be a source of knowledge. A part of the accompanying statements has a nostalgic touch, although this is a matter of interpretation, for instance in a statement like: 'Life used to be more quiet in the past than it is now'. ${ }^{16} \mathrm{Be}$ that as it may, there is insufficient evidence to consider nostalgia as the prevailing sentiment in this cluster but the statements do have a stronger emotional connotation than those in the first set. 
The third component refers to an aspect of the past that receives little support from genealogists. In the majority of statements, the past, especially our contemporary interest in it, is actually branded as an irrelevant matter. This for instance applies to a statement like: 'Looking back on the past is a senseless way to pass the time'. Genealogists clearly disagree with this negative attitude towards the past, as could be expected. The fact that the sentence 'I feel related to my ancestors' after statistical analysis turns up in this set of statements is less peculiar than it appears. Those who supported the other three assertions in this set were rather explicit in their rejection of this last statement. It should therefore be read as a negation. The existence of a relationship with one's ancestors and the positive appreciation of this relation, a defining feature of many genealogists, is in fact denied. To sum up, it may be said that where the first two sets refer to a more social or philosophical orientation towards history, in the third set a personal rejection of the past prevails.

No significant age and gender differences were found in the reactions to the statements. Yet, some other factors, amongst them educational level, appear to be of influence. The lower educated genealogists more often see history as being in contrast with the present than the more educated genealogists. A more pronounced 'history as contrast' attitude can also be observed among respondents whose family originates in the native region of the respondent.

We further found that the orientation of respondents towards the past affects their historical interest and activities. Agreement with the contention that history contrasts with the present tends to be accompanied by an interest in the more personal and familial aspects of historical culture. A stronger acceptance of the idea that history can be considered as irrelevant goes together with a smaller inclination to visit archives, museums, commemorative ceremonies and the like and with hardly experiencing a bond with the past when doing so. The same goes for the consumption of articles, books and other media products about the past. The appreciation of history as a source of knowledge is, on the other hand, coupled with a special interest in historical aspects that are more remote from the realities of daily life or one's own family history. As such, each of the three orientations towards the past appears to reflect a distinctive attitude that is related to various aspects of historical culture.

Since genealogists take up a rather distinctive position in their support and rejection of certain attitudes towards the past, it is interesting to compare them to respondents without such a particular historical interest. To that end, we made use of a survey that was administered among 125 non-genealogically interested respondents. ${ }^{17}$ The questionnaire included an assessment of attitudes towards the past, using the same twelve statements of the present study.

In Table 2, the questions that revealed a significant difference between genealogists and non-genealogists are printed in bold face,$^{18}$ taking into account possible age, gender and educational differences between both groups. With respect to history as a source of knowledge, genealogists prove to be even less convinced than the others that the past determines our current and future 
possibilities. Another difference can be found in the contrast-dimension. In comparison to the others, genealogists tend to disagree more with the proposition that in the past everything was different. Yet, all in all, genealogists and nongenealogists hardly differ in their opinion about history as a source of knowledge and as a contrast to the present.

\section{TABLE 2: ATTITUDES OF GENEALOGISTS AND NON-GENEALOGISTS TOWARDS PAST AND HISTORY (MEANS)}

\begin{tabular}{ll} 
StATEMENTS & Genealogists Non-genealogists \\
\hline
\end{tabular}

\section{Source of knowledge}

The past largely determines our current and future possibilities

Historical knowledge is of importance to understand the contemporary world.

Many developments and events repeat themselves in the course of history

\section{Contrast}

In the past, everything was different

The world is changing faster and faster

Life used to be more quiet in the past

than it is now

In the course of history things

keep getting better

\section{Irrelevant matter}

Looking back on the past is a senseless way to pass the time

The past is gone and means nothing to me

4.0

3.5 
The true difference between both groups is mainly to be found in their position on history as being irrelevant. As could be expected, genealogists consider history less as a senseless way to pass the time, less as something that is over and done and less as fiction in retrospect. They also feel themselves more strongly related to their ancestors. So, on the whole, we may safely conclude that they see history less often as an irrelevant matter, whereas with respect to the other two components the differences between both groups are few.

When we look to the non-genealogists as a whole, there are no gender or age differences in their historical attitude, as was also the case with the genealogists. However, the finding that the higher educated genealogists saw the past as a source of knowledge rather than as a contrast with the present also returns in the higher educated members of this group of respondents.

\section{CONCLUSION}

It is hardly surprising that genealogists associate the past and history with positive matters and that they nourish a vital interest in history. This is expressed in their interest in a broad range of eras, regions and topics and in a vast use of several sources of information. The attitude towards the past can, without any doubt, be characterised as positive. The Dutch genealogist does not consider the past to be irrelevant; it is a source of knowledge and provides a beneficial contrast to the present.

In addition, the analyses show also a specific interest. This is particularly defined as the period between 1500 and 1900, the respondent's place of residence and region, his or her family life and the personal course of life. Most of the genealogists are looking for those sources of information that reinforce an emotional connectedness to the past. History education in school has left behind an important impression for some, but not for the majority.

It therefore seems that a historical consciousness exists that does not by definition correspond to the concept which is cherished by those who feel uncomfortable with the contemporary historical culture in the Netherlands. The question is whether these critics show enough understanding for the specific historical interest of certain groups such as genealogists.

Genealogists clearly consider history as a source of knowledge by which they furthermore show the continuity that they experience between the present and the past. Placing the past in a larger historical framework, another characteristic of the traditional notion of historical consciousness - which is supposedly dwindling - is not something that is easily traced among genealogists. At least in this survey, no particularly strong indications of this have been found.

However, for the presence of aloofness towards the past, which to a certain extent is also considered to be desirable as part of this traditional notion of historical consciousness, there is on the one hand a positive indication: many genealogists clearly consider the past as different, as a contrast to the present. On the other, there seems to be less aloofness at the same time: genealogists do search the particularity of familiar areas of history such as their own region and 
their own family. Judging by their own definitions of terms, genealogists have more interest in the 'past' in the sense of what is close by and small-scale, and therefore almost directly accessible, than for 'history' in the sense of the authorized knowledge from the dominant historical canon. Nevertheless, the issue of accessibility should not be exaggerated: an awareness exists that the capacity to imagine the lives of previous generations has distinct restrictions.

We should not generalize about genealogists. For the case of the Netherlands, we have established that particularly the level of education and the connectedness with the region and place of residence influence the way in which history is perceived. Gender, in that perspective, seems to play only a limited role. In relation to historical interest, the activities connected to it and the three attitudes towards the past, only minor gender-related differences were observed. Remarkably, women are underrepresented in the active and organised hobby of genealogy unlike in the examples from North America. The fact that the usual angle in genealogical research - and in its presentation - consists of the male line in family relations (although there are other possibilities, such as a genderequal pedigree) does not seem to be a sufficient explanation. Further research could shed more light on this. Women's attitudes towards the past may possibly result in different hobbies and activities. ${ }^{19}$ Male and female genealogists seem to have a similar historical interest. This specific interest might be stronger among males in the population at large than among women, resulting in men more often choosing this particular hobby.

Genealogists with higher levels of education share the interests of those without similar educational backgrounds, but they have a broader interest, particularly with respect to larger geographical areas and to topics concerning society at large. Education and a geographical separation with the family past interpreted as separation from the region of origin of the family - seem to stimulate a stronger development of the traditional notion of historical consciousness in addition to an interest in family history.

Additional research, both in the Netherlands and elsewhere, is needed to explore the extent to which genealogists constitute a separate category concerning their perception and appreciation of history. As yet it is insufficiently clear how this group's relatively high average age was an influence, also considering that the group of non-genealogists used for comparative purposes was as well above the average Dutch age. It is plausible that interest in and reflection on the past will receive a more specific interpretation as one becomes older, while knowledge about history and experience of continuity and change increase. It remains a question if the average high age of active genealogists can be explained by the fact that, due to their (early) retirement, they finally have a good opportunity for such an often time-consuming hobby. It is more likely that this specific variety of historical interest appeals more strongly at such an age than in earlier stages of life. The popularity of genealogy as a hobby is not in the first place based upon the availability of sources and resources but is more presumably based on the fact that it is a variety of history that strongly captivates 
possible genealogists. It remains to be determined whether the pursuit of this hobby further influences historical interest and attitudes of the genealogists or whether it confirms already existing sensibilities.

From a comparative point of view, it would be interesting to study the group of people up to approximately forty years of age from which future genealogists will come. What attitudes towards the past do they have and how are these attitudes expressed? Furthermore, comparisons should be made not only with a group of average citizens, including a representative number of immigrants, but with other specific groups of historically interested people such as collectors, local (amateur) historians, heritage tourists and professional historians. Comparative research across national borders, including countries and societies that consider themselves relatively young as well as countries and societies that consider themselves older, would certainly increase the value of the outcomes. The study of the meaning of the past, linked to wider patterns of meanings and activities of groups and individuals, deserves serious attention in both the humanities and the social sciences.

\section{ENDNOTES}

\footnotetext{
${ }^{1}$ For an extensive treatment of this topic see Leen Dorsman, Ed Jonker, Kees Ribbens, Het zoet en het zuur. Geschiedenis in Nederland (Amsterdam 2000) and Kees Ribbens, Een eigentijds verleden. Alledaagse historische cultuur in Nederland, 1945-2000, Hilversum, 2002 pp9-12; 40-52; 285-289.

${ }^{2}$ For example see Frans Smits, "Bonifatius was een homo", Nederland doet proefwerk geschiedenis, Cijfer: een 4', Historisch Nieuwsblad, vol12, 2003, no 4, pp42-46. A more profound treatment is to be found in Magne Angvik, Bodo von Borries (eds), Youth \& history. A comparative European survey on historical consciousness and political attitudes among adolescents, Hamburg, 1997. For the Dutch case see Will Bouwman, Youth and history in Nederland. Het Europese onderzoek naar historisch besef bij jongeren en de resultaten in ons land nader bekeken, 's-Hertogenbosch, 1997.

${ }^{3}$ Nick Merriman, Beyond the glass case: The past, the heritage and the public in Britain, Leicester, 1991, pp3-4.

${ }^{4}$ Roy Rosenzweig and David Thelen, The presence of the past: Popular uses of history in American life, New York, 1998. The data from this survey are available at http://chnm.gmu.edu/survey/. Preliminary results of the project 'Australians and the past' are discussed in Paul Ashton and Paula Hamilton, 'At home with the past: Background and initial findings from the national survey', Australian Cultural History, no 22, 2003, pp5-30.

${ }^{5}$ The questionnaire 'The meaning of the past' was developed as part of Professor Dr P.M.M. Klep's initiative in Public History at Radboud University (then named Catholic University) Nijmegen, the Netherlands. It was made by the authors in association with prof. Klep and the psychologist Professor Dr J.A.P.J. Janssen. The authors would like to express their gratitude to these colleagues for their collaboration, as well as to Albert Logtenberg and Frank Reinders for their practical support and to J.F. van der Horst, general secretary of the NGVfor his kind assistance. The results were originally published as: Kees Ribbens, Gerben Westerhof and Cor van Halen, 'De betekenis van het verleden. De beleving en waardering van geschiedenis bij Nederlandse genealogen', Jaarboek van het Centraal Bureau voor Genealogie, vol 58, 200, pp225-245.

${ }^{6}$ Despite a certain increase in recent years, serious studies on genealogists are still relatively rare as Lambert observed in 1994 during his survey among 1348 members of the Ontario Genealogical Society. His study focused especially on the motives of the respondents for being involved with genealogical research. See Ronald D. Lambert, 'The family historian and temporal orientations towards the ancestral past', Time and society, vol 5, no 2, 1996, pp115-143; R.D. Lambert, 'A study or genealogists and family historians', Families, vol 34, no 2, 1995, pp73-80; no 3, pp149-160; no 4, pp223-232; vol 35, no 1, 1996, pp11-25. Also published in: The global gazette. Online family history magazine, vol 2, no 17, 1998; vol 3, no 5: http://globalgenealogy.com/globalgazette. More recent studies, using the internet, have been
} 
performed in North America by Pamela J. Drake (http://psych.fullerton.edu/genealogy/) and by the British sociologist and anthropologist Dr Kevin Meethan of the University or Plymouth (http://www.sociology.plymouth.ac.uk/ kmeethan/roots.htm). Present, Australian based research is being prepared by Kylie J. Veale at Curtin University of Technology, Perth, Australia.

${ }^{7} 192$ filled-in questionnaires were returned between early January and late February 2003. The data was then transferred to an SPSS-database. To place our response rate of $64 \%$ in context, we refer to Lambert's mail survey which has a response rate of $88,8 \%$ : Lambert, 'The family historian', pp115-143, especially pp118-119.

${ }^{8}$ Although not all Dutch people who pursue genealogy as a hobby are members of the NGV, the membership of this society represent the majority of somewhat advanced genealogists. It is likely that among those who are not members of the NGV, there will be a larger proportion of less experienced genealogists, younger genealogists, as well as persons who pursue this hobby less intensively.

${ }^{9}$ The mean age in the Canadian study was also in the early 60 s, although the exact number is not known: Lambert, 'The family historian', p120. Respondents in the American study by Drake had a mean age of 54 years, whereas the preliminary results of Meethan point to a mean age below 50 years. As no less than one out of five persons is older than 65 years, Drake concludes that the stereotype that genealogy is mainly an activity for older persons is not valid. The lower ages in studies by Drake and Meethan may be a result of the use of internet as a means of collecting data. Since older people use the internet less often they might be underrepresented in these studies. Jennifer Fulkerson, 'Climbing the family tree', American Demographics, vol 17, no 12, 1995, pp42-51. Cf. http://psych.fullerton.edu/genealogyl , Smolenyak Smolenyak, 'Who is the genealogist next door?', p17. For the Canadian study: Lambert, 'A study of genealogists and family historians', Families, vol 34, no 4, 1995, pp223-232.

${ }^{10}$ In the Canadian study conducted by Lambert in $199463 \%$ were female; in Drake's American study in 2001 it was $72.2 \%$. Lambert, 'The family historian', p120; http://psych.fullerton.edu/genealogy/.

${ }^{11}$ Lambert found that his respondents were educated rather well, more than half of them had higher educational levels. Lambert, 'A study of genealogists and family historians', Families, vol 34no 2, 1995, pp73-80.

${ }^{12}$ The respondents came from all across the country and were almost exclusively born in the Netherlands. Cf Lambert: 'the membership of the Ontario Genealogical Society reflects the composition of Ontario society as it once was, not as it now is.' Lambert, 'A study of genealogists and family historians', Families, vol 35, no 1, 1996, pp11-25.

${ }^{13}$ The word used in the questionnaire is 'jaartallen' which can be interpreted as both 'years' and 'dates'.

${ }^{14}$ This particular interest for adolescence has been often found in psychological studies on autobiographical memory. D.C. Rubin, T.A. Rahhal and L.W. Poon, 'Things learned early in adulthood are remembered best', Memory and Cognitio, vol 26, 1998, pp3-19.

${ }^{15}$ The usage of the terms 'history' and 'past' has been distributed as evenly as possible over the presented statements.

${ }^{16}$ Lambert pays summary attention to nostalgia (taken as the longing for a Canada in the former days) as a potential motivation to become a genealogist but in that context hardly finds any evidence for this. Lambert, 'The family historian', p131.

${ }^{17}$ The data of this survey have been collected in the Spring of 2004, as part of a bachelor training in psycho-gerontological research at Radboud University Nijmegen, The Netherlands. The authors would like to thank the students who, under the guidance of $\mathrm{Dr}$ G. Westerhof, have conducted 125 interviews in the circle of family members and acquaintances. Approximately as many men as women have been interviewed in three different age groups: 40-54, 55- 69 and 70-85 years.

${ }^{18}$ An average score of 1 means disagree strongly; 2, disagree somewhat; 3 , don't agree/don't disagree; 4 , agree somewhat and; 5 , agree strongly.

${ }^{19}$ Examining possible differences in appreciation between men and women with respect to Lambert's distinction between five aspects of genealogy (searching for information; registering information; sharing information with family members; keeping artefacts; and considering oneself as family historian) might be helpful. Cf. Lambert, 'A study of genealogists and family historians', Families, vol 34, no 3,1995, pp149160; vol 35, no 1, 1996, pp11-25. 